\title{
Clinical significance of atypical squamous cells of undetermined significance in detecting preinvasive cervical lesions in pre and post menopausal Albanian women
}

\author{
Demaliaj Eliona ${ }^{1}$ \\ Hoxha Eden² \\ ${ }^{1}$ Gynecology and Obstetrics, Ass. Prof. Medical University of Tirana, Tirana, Albania \\ ${ }^{2}$ Gynecology and Obstetrics, Matrix Medical Centre, Tirana, Albania
}

\section{Background:}

To evaluate the clinical significance of atypical squamous cells of undetermined significance (ASCUS) in PAP test in post-menopausal women and compare with pre -menopausal women.

\section{Methods:}

A total of 500 patients who referred to our gynecologic clinic in "Mbreteresha Geraldine" Hospital, Tirane, Albania, were included to the study between January 2012 and August 2014. Data for 194 post-menopausal (group 1) and 306 pre-menopausal (group 2) women with ASCUS cytology were evaluated.

\section{Patients interventions:}

Immediate colposcopy and endocervical curettage was performed for both groups and conization for all women with a result suggestive of CIN 2-3. HPV -DNA were assessed for all woman.

\section{Main outcome measures:}

Histopathological results and demographic features of patients were compared between the two groups. Results: Mean age of the patients was $54.6 \pm 6.5$ years in group 1 and $38 \pm 6.6$ years in group 2. Some $19(9.4 \%)$ of post- menopausal women and $49(15.9 \%)$ of pre-menopausal women were current smokers. No one was suffering from another disease.
Totals of post-menopausal and pre-menopausal women were assessed for HPV-DNA. HPV -DNA testing was performed by polymerase chain reaction (PCR) with $\mathrm{pU} 1 \mathrm{M} / \mathrm{pU} 2 \mathrm{R}$ primers in GENOMA Laboratory, Rome, Italy. High risk HPV was detected in $27(14 \%)$ and 85 (28\%), respectively ( $p=0.029)$. Final histopathological results recorded were normal cervix, low grade cervical intra-epithelial neoplasia (CIN 1), and high grade cervical intra-epithelial neoplasia (CIN2-3). In group 1, results were $84.8 \%, 12.2 \%$ and $1.8 \%$, respectively, and in group 2 were $71.9 \%, 23.2 \%$ and $4.9 \%$. Two cases were detected as micro-invasive carcinoma in pre-menopausal group (1\%). Two cases were detected as endometrial carcinoma in the menopausal group $(0.6 \%)$.

\section{Conclusions:}

In current study we found that preinvasive lesions were statistically significantly higher in pre-menopausal women than post-menopausal women with ASCUS. High risk HPV were significantly higher in pre-menopausal women. Cervicitis was more common in menopausal women. 